\title{
Clino-Pathological Correlation of Dermatological Manifestations in People Living with HIV/AIDS (PLHIV) at a Tertiary Care Hospital, Western India
}

\author{
Poonam Chakubhai Radadiya and Aditi Dinesh Dholakia*
}

Pathology Department, GMERS, Medical college, Gotri, Vadodara, India

\begin{abstract}
Background: A large number of skin conditions that might present to a dermatologist ranging from infectious to benign to malignant in HIV positive patients. Many of them need detailed and time consuming investigations to confirm the clinical diagnosis. Probably skin biopsy is the most important ancillary aid to confirm the clinical diagnosis. Skin biopsies play a vital diagnostic role when different diseases present with clinically similar skin lesions. A diagnostic approach is given based on the predominant histological reaction pattern, with an emphasis on clinicopathological correlation. So, this study tries to assess the clinic-pathological correlation in dermatological manifestations in PLHIV.

Methods: Punch biopsies from the skin lesions were studied from March 2016 to April 2017 with routine histopathology examination and special stains were used as and when required. Clinical diagnosis was then correlated with histopathological examination.

Result: A total of 60 punch biopsies of PLHIV were studied. 22 (36.66\%) patients had infectious lesions and 38 (63.33\%) patients had noninfectious lesions. Correlation of Clinical diagnosis was done with histopathological findings, which showed $88.8 \%$ of papular lesions well correlated histopathologically. Only $33 \%$ of malignant and premalignant skin conditions were diagnosed correctly on clinical examination. Overall, $68.33 \%$ of cases including non-neoplastic and neoplastic lesions, showed clinic-pathological consistency.
\end{abstract}

Conclusion: Skin biopsy and clinicopathological correlation is clearly a worthwhile investigative procedure.

Keywords: Biopsy, Clinicopathological Correlation, Histopathology, Infectious Lesions, Skin Lesions

\section{Introduction}

HIV infection constitutes a major health problem worldwide. ${ }^{[1-3]}$ India has the third largest HIV epidemic in the world with an estimated adult prevalence of $0.26 \% \cdot{ }^{[4]}$ Diseases of skin and mucous membranes are common clinical manifestations of acquired immunodeficiency syndrome (AIDS) causing significant morbidity among PLHIV. ${ }^{[5]}$ Dermatological lesions in PLHIV can present with a variety of manifestations. ${ }^{[6,7]}$ Moreover, dermatological manifestations may be the initial signs of immunesuppression. ${ }^{[8]}$ They affect between 80 and $95 \%$ of PLHIV occurring at any point of time during the course of infection. ${ }^{[9,10]}$ In majority of PLHHIV cases, skin is often the first and only organ affected at the time of presentation as well as most of course of infection. . $^{[9,11,12]}$ Cutaneous disorders during HIV infection are numerous. ${ }^{[13,14]}$ Some Cutaneous disorders reflect the progression of HIV disease, but this relation is still controversial. ${ }^{[14,15]}$ Extensive HIV-related literature has focused on distinctive clinical presentations such as Kaposi's sarcoma, oral hairy leukoplakia, and oral candidiasis. ${ }^{[13,15]}$ However, the findings on careful skin examination of HIV infected patients who present for primary care have received limited attention.
In this study, we aimed to describe the dermatological manifestations of PLHIV on initial presentation and its correlation with histopathological findings.

\section{Materials and Methods}

This descriptive cross-sectional study was conducted at a tertiary care hospital (B J Medical College, Ahmedabad) from March 2016 to April 2017. Information on PLHIV were collected from ART center and from counseling center and all participants testing positive for HIV were enrolled for ongoing study. There were no specific eligibility criteria. All PLHIV who accessed care at hospital were included. Information on demographics, that is, age, sex and socioeconomic status was noted. A complete medical history and physical examination of patients were done by a dermatologist for optimal evaluation and dermatologic lesions were diagnosed on the basis of clinical appearance. Informed consent was taken from the PLHIV for skin biopsy procedure. After detailed general and local examination, the site of the biopsy was selected. All universal aseptic precautions according to National AIDS Control Organization guidelines were followed. The selected patient's written consent was taken after explaining the details of the biopsy procedure. All 
skin biopsies were taken under local anesthesia. The three dimensional size and shape of the skin biopsy were assessed including the circular or elliptical shape of the biopsy for gross examination. The biopsy obtained was processed by standard formalin fixing paraffin embedding method. Serial sections and special stains were studied as and when required. We have used diagnostic technique of clinical evaluation by a dermatologist along with histopathological examination of skin biopsy for dermatological disorders in PLHIV. The obtained data was analyzed. The Clinical diagnosis obtained from dermatologist and histopathological diagnosis were correlated.

\section{Result}

Out of total 60 PLHIV included in the present study, 43 were males and 17 were female patients. In present study, Age range of the study participants was between 20 to 60 years. Among that, 20 patients $(33.3 \%)$ were between 21 to 30 years of age and 25 patients $(41.6 \%)$ were between 31 to 40 years. This makes 21 to 40 years of age most common age of presentation in present study.

Among 60 patients studied, most common provisional clinical diagnosis was bacterial infections $13(21.6 \%)$ followed by papular lesions 09 (15\%).(Table 1)

All the 60 cases were subjected to biopsy and histopathological examination. Out of this 60 cases, 22 (36.66\%) had infectious pathology, whereas $35(58.33 \%)$ patients had non- infectious pathology, where as only $3(5 \%)$ cases were fell into malignant/premalignant category. (Table 1)

Among infectious skin pathologies, variety of infections were observed such as viral, bacterial, fungal and parasitic (Arthropod) infections. Total 08 (13.3\%) patients had bacterial infections, which included mainly leprosy, folliculitis, and syphilis. Total 07 (11.6\%) patients showing viral pathology included Molluscum contagiosum, human papilloma virus (HPV), herpes zoster and herpes simplex virus (HSV). Total fungal infections noted were 06 (10\%), which included candidiasis, dermatophytoses-tinea, cryptococcosis and histoplasmosis. Only a single (1.6\%) case of parasitic infections was diagnosed as dermal leishmaniasis. Total four patients had vascular lesion and two patients had other non-specific pathology including follicular keratosis and perforating keratosis. (Table-1)

All the clinical diagnosis was correlated with histolopathological diagnosis. Overall, $68.33 \%$ of cases including non-neoplastic and neoplastic, shown consistency between clinical and histopathological diagnosis. (Table-2 \& 3).On correlation between both the diagnosis, it was found that $88.8 \%$ of papular lesions diagnosed clinically were well correlated histopathologically, whereas clinicohistopathological correlation was only $33 \%$ in cases of malignant and premalignant skin conditions.

Table 1: Provisional clinical diagnosis and histopathological diagnosis among PLHIV

\begin{tabular}{|c|c|c|c|c|}
\hline \multirow[b]{2}{*}{ Diagnosis } & \multicolumn{2}{|c|}{ Clinical } & \multicolumn{2}{|c|}{ Histopathological } \\
\hline & $\begin{array}{l}\text { Number } \\
(n=60)\end{array}$ & $\%$ & $\begin{array}{l}\text { Number } \\
(n=60)\end{array}$ & $\%$ \\
\hline $\begin{array}{l}\text { A. Dermatitis:- Atopic Dermatitis, Ashy Dermatitis, Urticaria, Hyperpigmented } \\
\text { patch, chronic non-specific dermatitis. }\end{array}$ & 08 & 13.3 & 08 & 13.3 \\
\hline $\begin{array}{l}\text { B. Papular lesion:- Pruritic papular, Psoriasis, Seborrhoic Dermatitis, } \\
\text { Eosinophilic folliculitis, Scaly lesion, Lichen planus }\end{array}$ & 09 & 15.0 & 10 & 16.6 \\
\hline C. Epidermal Lesion:- Epidermoid cyst, Seborrhoic keratosis & 03 & 5.0 & 03 & 5.0 \\
\hline D. Viral lesions:- Warts, Condyloma Lata, Molluscum contagiosum & 08 & 13.3 & 07 & 11.6 \\
\hline $\begin{array}{l}\text { E. Bacterial infections:-Chanchroid, Hansens, Tuberculosis verrucosa } \\
\text { cutis, Folliculitis, Pustular lesion, Lupus vulgaris, Syphilis, Pyoderma } \\
\text { gangrenosum. }\end{array}$ & 13 & 21.6 & 08 & 13.3 \\
\hline $\begin{array}{l}\text { F. Fungal infections:- Candidiasis, Cryptococcus, Histoplasma, } \\
\text { TineaCorporis }\end{array}$ & 05 & 8.3 & 06 & 10 \\
\hline G. Parasitic \&Protozoal infections:- Leishmaniasis, Scabies & - & - & 01 & 1.6 \\
\hline H. Drug reaction & - & - & - & - \\
\hline I. Vascular lesion:- Leukocytoclastic vasculitis, Granuloma Pyogenicum & 02 & 3.3 & 04 & 6.6 \\
\hline J. Connective tissue lesion:- DLE, Granuloma Annulare & 04 & 6.6 & 04 & 6.6 \\
\hline $\begin{array}{l}\text { K. Malignant/Premalignant lesion:- Verrucous Carcinoma, Squamous } \\
\text { cell carcinoma, Bowenoid papulosis }\end{array}$ & 03 & 5.0 & 03 & 5.0 \\
\hline $\begin{array}{l}\text { L. Vesiculobullous lesion:- Pemphigus vulgaris, Bullous pemphigoid, } \\
\text { Bullous impetigo, ErythemaMultiforme }\end{array}$ & 04 & 6.6 & 04 & 6.6 \\
\hline M. Others:- Follicular keratosis, Perforating folliculitis & 01 & 1.6 & 02 & 3.3 \\
\hline
\end{tabular}


Table 2: Correlation between Clinical diagnosis with Histopathological diagnosis among study participants (n=60).

\begin{tabular}{|c|c|c|c|}
\hline Category & $\begin{array}{c}\text { Total no } \\
\text { Of cases }\end{array}$ & $\begin{array}{c}\text { Cases Correlated } \\
\text { histopathologically }\end{array}$ & $\begin{array}{c}\text { Cases not correlated } \\
\text { histopathologically }\end{array}$ \\
\hline Dermatitis & 08 & 06 & 02 \\
\hline Papular & 09 & 08 & 01 \\
\hline Epidermal & 03 & 02 & 01 \\
\hline Viral & 08 & 07 & 01 \\
\hline Bacterial & 13 & 09 & 04 \\
\hline Fungal & 05 & 05 & 00 \\
\hline Parasitic & 00 & 00 & 00 \\
\hline Vascular & 02 & 02 & 01 \\
\hline Connective tissue & 04 & 03 & 01 \\
\hline Malignant/Premalignant & 03 & 03 & 01 \\
\hline Vesiculo-bullous & 04 & 01 & 00 \\
\hline Other & 01 & 03 & 01 \\
\hline
\end{tabular}

Table 3; Clinico-pathological correlation of benign and malignant/premalignant category among skin lesions of study participants.

\begin{tabular}{|l|c|c|c|}
\hline Category & Correlated histologically & $\begin{array}{c}\text { Not correlated } \\
\text { histologically }\end{array}$ & $\begin{array}{c}\text { Chi-square } \\
\text { (p -value) }\end{array}$ \\
\hline Benign & 40 & 17 & 0.49 \\
Malignant/premalignant & 01 & 02 & $(0.48)^{*}$ \\
\hline
\end{tabular}

*not significant statistically

\section{Discussion}

The dermatological manifestations including many opportunistic skin infections, are quite common in HIV infected patients. ${ }^{[6,7]}$ More than $90 \%$ of human immunodeficiency virus infected patients develop skin lesions at some point of time through the course of disease. [16] This study was mainly focused on the dermatological manifestations of PLHIV attending a tertiary care center for treatment. All the 60 patients included in the study are already diagnosed positive for HIV infection.

The majority $(90 \%)$ of the infected patients in this study belonged to rural areas and belonged to lower socioeconomic strata (79.4\%). This indicates poor nutritional status, which itself can accelerate the progression of HIV infection.

In present study, age range of all the sixty patients was between 21 to 60 years. Out of these 60 patients, 25 patients (41.67\%) were between 31 to 40 years of age. Similar findings have been observed in study done by Sanjay M. Chawhan et al, where maximum patients were falling in the same age range. ${ }^{[16]}$

In the present study, we found $71.6 \%$ male patients as compared to $28.3 \%$ female patients, with 2.5 : 1 male to female ratio. Similarly, male preponderance has been observed by other authors. ${ }^{[16,17]}$
Maximum number of provisional clinical diagnosis obtained in present study, were bacterial infections, papular lesions and dermatitis.

In present study, histopathological examination of skin biopsy revealed that, maximum patients were having bacterial skin infection with Mycobacterium infections was the most common. Among these mycobacterium infections, we found $7(11.6 \%)$ cases of leprosy which included four cases of borderline tuberculoid and one case from each of tuberculoid leprosy, papulonecrotic tuberculid and erythema nodosum leprosum. Harminder singh et al also found leprosy as the most common dermatological disorder in HIV positive patients. ${ }^{[18]}$

Among other skin infections, we found 07 (11.6\%) patients with viral lesions, $06(10 \%)$ patients with fungal infections and $01(1.6 \%)$ patient with parasitic lesion diagnosed as dermal leishmaniasis. Out of total six cases of fungal cutaneous infections, there were two cases of cryptococcosis and histoplasmosis (one from each). This shows that in HIV seropositive patients, infectious agents can produce skin lesions even though the classic organs of involvement by these agents do not include the skin.

In present study, total 35 cases were diagnosed as nonneoplastic and non-infectious lesions on histopathological 
diagnosis. In this category, papulo-pruritic lesions like Pruritic papular eruptions, Psoriasis, Seborrhoic Dermatitis, Eosinophilic folliculitis, Scaly lesion, Lichen planus were the most prevalent; followed by dermatitis. The study done by Sanjay M. Chawhan et al. also shows papulopruritic eruptions as a most common non-neoplastic lesion diagnosed in PLHIV. ${ }^{[16]}$

In present study, we found only three cases of malignant/ premalignant skin lesions, which includes verrucous carcinoma, squamous cell carcinoma and bowenoid papulosis. Wiwanitkit (2004), D. N. Lanjewar (2011) and Sanjay M. Chawhan (2013) also found striking low prevalence of cutaneous and other malignancies in PLHIV. ${ }^{[6,19,16]}$ In this study, no any case of Kaposi's sarcoma or lymphoma was found.

Practicing general anatomical pathologists and dermatopathologists, especially those working in regions where HIV/AIDS is highly prevalent, must be familiar with the spectrum of cutaneous manifestations of HIV/AIDS.

The provisional clinical diagnosis of all the 60 patients were recorded and subsequently correlated with their histolopathological diagnosis. The clinico-pathological consistency was found in 40 cases $(68.33 \%)$ out of 60 . A Study done by Jyoti Singh Rajput et al, also has clinicopathological consistency in $75 \%$ cases. ${ }^{[20]}$ This diagnostic consistency was maximum in cases of papular lesion, where 8 out of 9 cases $(88.8 \%)$ of papular lesions diagnosed clinically, were well correlated histopathologically. Whereas, in only one case of bowenoid papulosis out of three cases of malignant and premalignant category was correctly correlated with histopathological diagnoses. Thus, it is very important to subject every skin lesion to histopathological examination for confirmation of diagnosis and proper treatment plan of the patient. An erroneous clinical diagnosis and failure to perform a confirmatory skin biopsy will inevitably delay proper provision of therapy. ${ }^{[21]}$

Many of the skin lesions in PLHIV can show atypical/ unusual clinical presentations.

In present study, one patient with Histoplasmosis infection presented with multiple nodular lesions on face and upper trunk, was given provisional clinical diagnosis of seborrhoic keratosis. Other diverse presentations like erythematous macules, molluscum contagiosum-like papules or nodules, a guttate psoriasis-like eruption or purpuric lesion can be found in PLHIV infected with Histopasmosis. ${ }^{[21]}$ It is worth mentioning that, diverse clinical presentation of certain clinical conditions in HIV patients results in failure to establish proper clinical diagnosis. ${ }^{[21]}$ In such cases, histopathological examination proves to be very essential for confirmation of diagnosis. Also it is very important on the part of a histopathologist to maintain a high index of suspicion for undiagnosed HIV/AIDS when clinical history indicates that a common dermatosis has displayed unusual/atypical clinical features. ${ }^{[21]}$

An ulceration of overlying epidermis is not an uncommon presentation in any of infective or neoplastic dermatological conditions in PLHIV. ${ }^{[21]}$ Such ulcerative lesions need to be investigated thoroughly. In present study, one case of ulcerative lesion on genital region which was clinically diagnosed as chanchroid, on histopathologically, it turned out to be non-keratinizing SCC.

Similarly, a case of dermal leishmaniasis, presented with multiple papular, erythematous, scaly lesions over face of 1 and $1 / 2$ month duration and was given the provisional clinical diagnosis of Amyloidosis. On histopathological examination of biopsy, it was diagnosed as dermal leishmaniasis.

It was also observed that, submitting skin biopsy with a differential diagnosis improves chances of more corrective diagnosis. ${ }^{[20]}$ In present study, six cases were given with more than one provisional clinical diagnosis and subsequently one confirmed diagnosis on histopathological examination was given.

In present study, on histopathological examination revealed, periadnexal and perivascular inflammatory infiltrate, i.e., lymphocytic infiltration was the common finding irrespective of type of pathology. None of the lesions showed normal epidermis. Epidermal hyperplasia in the form of acanthosis, irregular parakeratosis or hyperkeratosis was seen in most of the lesions.

\section{Conclusion}

We found that the dermatological manifestations have high prevalence among HIV positive subjects; of these, papular lesions and infectious lesions are most common. Thus, patients with skin complaints should be motivated for HIV testing as dermatological manifestations can be a common clinical presentation in PLHIV patients. This also reiterates the need for thorough skin examination in HIV positive patients and provision of optimal medical care to these patients.

As with dermatopathology in general, careful clinicpathological correlation is of paramount importance for making confirm diagnosis and proper treatment planning of patient. Histopathologists practising in regions of the world where HIV/AIDS is prevalent must be familiar with the diverse spectrum of presentation of HIV related 
cutaneous pathology. There should be a high index of suspicion for HIV-related skin pathology if a biopsy is obtained from a patient whose skin disease has an atypical clinical presentation, or if that disease has failed to respond to conventional therapy. Skin biopsy material from HIV positive patients should always be carefully examined for more than one pathological process.

\section{Reference}

1. Bravo IM, Correnti M, Escalona L, Perrone M, Brito A, Tovar V, et al. Prevalence of oral lesions in HIV patients related to CD4 cell count and viral load in a Venezuelan population. Med Oral Patol Oral Cir Bucal.2006;11:E1-5.

2. Ranganathan K, Umadevi M, Saraswathi TR, Kumarasamy N, Solomon S, Johnson N, et al. Oral lesions and conditions associated with Human Immu-nodeficiency Virus infection in 1000 South Indian patients. Ann Acad Med Singapore.2004;33:37-42.

3. Moniaci D, Greco D, Flecchia G, Raitieri R, Sinicco A. Epidemiology, clinical features and prognostic value of HIV1 related oral lesions. J Oral Pathol Med.1990;19:477-81.

4. NACO (2015) 'Annual report 2015-16'.

5. Cedeno-Laurent F, Gomez-Flores M, Mendez N, Ancer-Rodriguez J, Bryant JL, Gaspari AA, et al. New insights into HIV-1-primary skin disorders. J int AIDS soc.,2011jan24.14:5.

6. Wiwanitkit V. Prevalence of dermatological disorders in Thai HIV-infected patients correlated with different CD4 lymphocyte count statuses: A note on 120 cases. Int J Dermatol.2004;43:265-8.

7. Kumarasamy N, Solomon S, Madhivanan P, Ravikumar B, Thyagarajan SP, Yesudian P, et al. Dermatologic manifestations among human immunodeficiency virus patients in south India. Int J Dermatol.2000;39:192-5.

8. Coopman SA, Johnson RA, Platt R, Stern R. Cutaneous disease and drug reactions in HIV Infection. $\mathrm{N}$ Engl $\mathrm{J}$ Med.1993;328:1670-4.

9. Tschachler E, Bergstresser PR, Sting 1G. HIV-related skin diseases. Lancet.1996;348:659-63.
10. Uthayakumar S, Nandwani R, Drinkwater T, Nayagam AT, Darley CR. The prevalence of skin disease in HIV infection and its relationship to the degree of immunosuppression. $\mathrm{Br}$ J Dermatol.1997;137:595-8.

11. Goldstein B, Berman B, Sukeni kE, Frankel SJ. Correlation of skin disorders with CD4 lymphocyte counts in patients with HIV/AIDS. J Am Acad Dermatol.1997;36:262-4.

12. Smith KJ, Skelton HG, Yeager J. Cutaneous findings in HIV1 positive patients: A 42-month prospective study. J Am Acad Dermatol.1994;31:746-54.

13. Coopman SA, Johnson RA, Platt R, Stern RS. Cutaneous disease and drug reactions in HIV infection. N Engl J Med.1993;328:1670-4.

14. Goodman DS, Teplitz ED, Wishner A. Prevalence of Cutaneous disease in patients with AIDS or AIDS-related complex. J Am Acad Dermatol.1987;17:210-20.

15. Coldiron BM, Bergstresser PR. Prevalence and clinical spectrum of skin disease in Patients infected with HIV. Arch Dermatol.1989;125:357-61.

16. Chawhan SM, Bhat DM, Solanke SM. Dermatological manifestations in human immunodeficiency virus infected patients: Morphological spectrum with CD4 correlation. Indian J Sex Transm Dis.2013 Jul-Dec;34(2):89-94.

17. Jindal N, Aggarawal A. HIV seropositive and HIV associated dermatosis among patients presenting with skin and mucocutaneous disorders. Indian journal of dermatology, venerology andleprology. 2009;75:283-286.

18. Singh H, Singh P, Tiwari P, Dey V, Dulhani N, Singh A, et al. Dermatological manifestations in hiv-infected patients at a tertiary care hospital in a tribal (bastar) region of chhattisgarh, india. Indian J Dermatol.2009Oct-Dec;54(4):338-341

19. Lanjewar DN. The spectrum of clinical and pathological manifestations of AIDS in a consecutive series of 236 autopsied cases in mumbai, India. Patholog Res Int 2011. 2011547618.

20. Rajput JS, Singh K, Singh S, Singh A. Clinico-pathological study of non-neoplastic skin disorders. MedPulseInternational Medical Journal August 2014;1(8):367-372.

21. Grayson W. The HIV positive skin biopsy. J Clin Pathol 2008;61:802-817.

*Corresponding author:

Dr. Aditi D. Dholakia, Assistant Professor, Pathology Department, GMERS, Medical college, Gotri, Vadodara, Gujarat, India

Phone: +91 0265 2681124, 9824313724

Email: dharmeshvasavada@gmail.com

Financial or other Competing Interests: None. 